có ý nghĩa thống kê. Kết quả NC bảng 6 cũng cho thấy triệu chứng ho không hiệu quả là yếu tỗ nguy cơ có liên quan đến tình trạng viêm phổi. Tỷ lệ $B N$ ho không hiệu quả trong nhóm viêm phổi cao hơn nhóm không viêm phổi, có sự khác biệt có ý nghĩa thống kê. Nguy cơ mắc viêm phổi ở nhóm ho không hiệu quả cao hơn 20 lần so với nhóm ho có hiệu quả $\mathrm{OR}=20(4,8-$ $82,2)$, có sự khác biệt có ý nghĩa thống kê với $p$ $<0,05$. Kết quả này cũng giống với $\mathrm{NC}$ của Nguyễn Thị Dung nguy cơ viêm phổi của nhóm ho không hiệu quả cao nhóm ho hiệu quả.

\section{KẾT LUÂ̂N}

1. Tỷ lệ BN tham gia NC trên 70 tuổi khá cao là 46,6\%. Độ tuổi trung bình: 69,2 \pm 12,90.

- Tỷ lệ BN có RLN khá cao 38,4\%. Nam giới mắc nhiều hơn nữ giới.

2. Một số yếu tố nguy cơ liên quan nổi trội của RLN: Độ tuổi cao, nam giới có nguy cơ bị rối loạn nuốt cao hơn nữ. BN có tình trạng ý thức thông qua điểm Glasgow thấp có nguy cơ bị rối loạn nuốt cao hơn nhóm BN có điểm Glasgow 15 điểm. Nguy cơ mắc viêm phổi ở nhóm ho không hiệu quả cao hơn so với nhóm ho có hiệu quả.

\section{KIẾN NGH!}

1. Tất cả các bệnh nhân đột qụy cấp nên được sàng lọc RLN bởi các thang sàng lọc sớm (GUSS) ngay sau khi nhập viện tại các khoa cấp cứu và thần kinh.
2. Đào tạo nhân viên để tham gia trị liệu rối loạn nuốt cho bệnh nhân tại các khoa Thần kinh bệnh viện tuyến tỉnh để nâng cao chất lượng điêu trị và chăm sóc bênh nhân đột qụy ở giai đoạn cấp.

\section{TÀI LIẸU THAM KHẢO}

1. Phan Nhưt Trí (2011), "Nghiên cứu rối loan nuốt ở bệnh nhân tai biên mạch não cấp tại Bệnh Viện Cà M̉au năm 2010", Luận văn Bác sỹ chuyên khoa cấp II, Đại học y Hà Nội.

2. Trần Văn Minh (2002), "Nighiên cứu biến chứng sắc phổi ở các bênh nhân điều tri hồi sức cấp cứu và̀ chông độc", Luân văn Bác sỹ CKİI, Đại học Y HN.

3. Adam et al (2007). "Guiline for the Early Management of Adult with Ischemic Stroke". Circilation 2007. $478-534$.

4. Martino et al (2006), "Management of Dysphagia in Acute Stroke: An Educational Manual for the Dysphagia Screening Professional", The Heart and Stroke Foundation of Ontario, ] A N U A RY 2006

5. Nguyễn Thị Dung (2014). Bước đầu tìm hiểu rối loạn nuốt và nhu câu can thiệp PHCN nuốt ở bệnh nhân tai biến mach máu não. Luận văn bác sĩ nội trú. Đại học Y Hă Nội.

6. Falsetti $P$ et al (2009). Oropharyngeal dysphagia after stroke: insidence, diagnosis, and clinical predictors in patients admitted to a neurorehabilitation unit. ] stroke cerebrovasc Dis; 18: 329-335.

7. D. Kidd et al (1993), "Aspiration in acute stroke: a clinical study with videofluoroscopy", Quarterly journal of Medicine, 1993; 86:825-829.

8. C.Gordon et al (1987), "Dysphagia in acute stroke", British Medical Journal, volume 29515 August 1987.

\title{
KHẢO SÁT MỐI LIÊN QUAN GIỮA MỨC Độ HồI PHỤC KHI RA VIÊ̂N VỚI MộT SỐ THANG ĐIỂM CỦA BÊ̂NH NHÂN ĐộT QUỴ NHỒI MÁU NÃO KHÔNG DO NGUYÊN NHÂN TỪ TIM
}

\author{
Nguyễn Văn Quốc ${ }^{1}$, Dương Văn Duy ${ }^{2}$, Nguyễn Trung Kiên ${ }^{2}$, \\ Trương Xuân Dương², Nguyễn Quang $\mathrm{Huy}^{2}$, \\ Nguyễn Thái Sơn ${ }^{2}$, Đặng Phúc Đức
}

\section{TÓM TẮT}

Mục tiêu: Nhận xét các yếu tố nguy cơ, đặc điểm lâm sàng và các thang điểm đột quỵ của BN Đột quy. nhồi máu não cấp không do nguyên nhân từ tim và̀

${ }^{1}$ Hệ Sau đại học, Học viện Quân Y

${ }^{2}$ Hề Đại học, Học viện Quân Y

${ }^{3}$ Bềnh viện Quấn Y 103

Chịu trách nhiệm chính: Nguyễn Văn Quốc

Email: bs.vanquoc@gmail.com

Ngày nhận bài: 5.3.2021

Ngày phản biên khoa học: 22.4.2021

Ngày duyệt bài: 7.5.2021 khảo sát mối liên quan giữa mức độ hồi phuc khi ra viện với các thang điểm đột quy. Đối tượng và phương pháp: 159 BN Đột quy nhồi máu não lần đâu khônng do nguyên nhân từ tim được điều trị tại Khoa Đôt quy, Bếnh viên Quân y 103 từ tháng 6/2020 đến tháng 1/2021, thời gian nhập viện dưới 7 ngày tính từ khi khởi phát. Kểt quả: Các yếu tố nguy cơ đột quy: tuổi $\geq 55$ 83,6\%, nam 64,8\%, tăng huyết áp $51,6 \%$, đái tháo đường $11,9 \%$, rối loạn lipid $26,4 \%$, béo phì $15,7 \%$, hút thuốc lá $29,6 \%$ và uống rượu bia 30,4\%. Các thang điểm lúc nhập viên: Điểm GCS trung bình $14,41 \pm 1,31$ GCS = 15 điểm là 74,2\%; điểm NIHSS trung bình 7,47 $\pm 5,80$, NIHSS $<5$ điểm là $39,6 \%$ và điểm ASPECT trung bình $7,87 \pm 1,39$, 
ASPECT > 7 là 71,7\%. Lúc ra viện điểm mRS trung bình là $2,19 \pm 1,34, \mathrm{mRS} \leq 2$ là $72,3 \%$. Có mối liên quan giứa mức độ hồi phục khi ra viện theo thang điểm $\mathrm{mRS}$ với thang điểm GCS $(\mathrm{p}=0,002, \mathrm{OR}=3$ $(1,5-6,8)), \operatorname{NIHSS}(p<0,01$, OR $=7,2(2,8-18,2))$ và $A$ SPECT $(p=0,029, O R=2,3(1,1-4,7))$. Tuy nhiên khi phân tích hồi quy logistic đa biến thì chỉ có thang điểm NIHSS là có tương quan với $m R S(r<0,001)$ và dự báo được kết quả hồi phục ra viện. Kết luận: Thang điểm GCS, NIHSS và ASPECT có mối liên quan với mức độ hồi phục khi ra viện được đánh giá theo thang điểm mRS. Tuy nhiên chỉ có thang điểm NIHSS có giá trị hậu dự báo được mức độ hồi phục lúc ra viện.

Tư khóa: Đột quy nhồi máu não, hồi phục, mRS, NIHSS, GCS, ASPECT.

Viết tắt: $\mathrm{BN}=$ bệnh nhân; GCS = Glasgow Coma Scale (thang điểm hôn mê Glasgow); NIHSS = National Institute of Health Stroke Scale (thang điểm đôtt quy của Viên Sức khỏe quốc gia Hoa Kỳ); mRS = modified Rankin Scale (thang điểm Rankin sửa đổi); ASPECT $=$ Alberta Stroke Program Early CT Score.

\section{SUMMARY}

INVESTIGATE THE RELATIONSHIP BETWEEN THE OUTCOME AT DISCHARGE AND SOME STROKE SCALES OF PATIENTS WITH A NON-CARDIAC ISCHEMIC STROKE

Objective: To evaluate risk factors, clinical characteristics and some stroke scales of the patients with a non-cardiac ischemic stroke and the relations between outcome and some stroke scales. Subjects and methods: 159 patients with non-cardiac ischemic stroke for the first time treated at the Department of Stroke, Military Hospital 103 from June 2020 to January 2021. They admitted to the hospital during the first 7 days. Results: Risk factors: age $\geq$ $5583.6 \%$, male $64.8 \%$, hypertension $51.6 \%$, diabetes $11.9 \%$, lipid disorder $26.4 \%$, obesity $15.7 \%$, smoke $29.6 \%$ and drink alcohol $30.4 \%$. The scale at admission: the average of GCS $14.41 \pm 2.31$, GCS $=$ 15 was $74.2 \%$; the average of NIHSS was $7.47 \pm 5.80$ the NIHSS $<5$ was $39.6 \%$ and the average of ASPECT was $7.87 \pm 1.39$, and the ASPECT $>7$ was $71.7 \%$. At discharge, the average of mRS was $2.19 \pm 1.338$, mRS $\leq 2$ was $72.3 \%$. There was a correlation between the level of outcome according to the mRS with the GCS OR $=3(1.5-6.8)(p=0.002)$, NIHSS OR $=\mathrm{OR}=7.2(2.8-18.2) ; \mathrm{p}<0,01)$ and ASPECT OR = $2.3(1.1-4.7)(p=0.029)$. However, when analyzing multivariate logistic regression, only NIHSS had correlation with mRS $(r<0.001)$ and could be used to predict the level of outcome.. Conclusion: The GCS, NIHSS and ASPECT scales were associated with outcome according to the mRS. However, only the NIHSS was able to predict the outcome at discharge.

Key words: ischemic stroke, outcome, mRS, NIHSS, GCS, ASPECT.

\section{I. ĐĂT VẤN ĐỀ}

Đột quy, trước đây được gọi tai biến mạch máu não, là nguyên nhân thứ hai gây tử vong và là nguyên nhân thứ ba gây ra di chứng tàn tật trên toàn thế giới. [1] Đột quỵ. vẫn là một vấn đề sức khỏe toàn cầu lớn và tầm quan trọng của nó có thể sẽ tăng lên trong tương lai do sự già hóa dân số ở các nước đang phát triển. [2] Đột quy. được phân thành hai loại chính: thiếu máu và chảy máu; trong đó đột quy do thiếu máu là phổ biến nhất chiếm $85 \%$, trong khi đó đột quy chảy máu chiếm $15 \%$.[3] Nghiên cứu toàn cầu về bệnh tật năm 2013 cho thấy tỷ lệ mắc chuẩn hóa theo tuổi, tỷ lệ tử vong, tỷ lệ mắc bệnh, số năm sống được điều chỉnh theo tàn tật (DALYs) và số năm sống trong tình trạng khuyết tật đã giảm mặc dù số lượng người đột quy tăng từ năm 1990 đến 2013. Ước tính có gần 25,7 triệu người sống sót sau đột quy. ( $71 \%$ bị đột quy do thiếu máu) và 6,5 triệu người chết vì đột quy. (51\% chết vì đột quy do thiếu máu). [4]

Việc tiên lượng hậu dự báo hồi phục chức năng khi ra viện bằng thang điểm mRS sau đột quy. đã có nhiều nghiên cứu sử dụng một số thang điểm lâm sàng để đánh giá như thang điểm GCS, NIHSS và ASPECTS. Tuy nhiên, không nhiều nghiên cứu đánh giá mối liên quan của chúng. Do đó chúng tôi tiến hành nghiên cứu này nhằm: nhận xét các yếu tố nguy cơ, đặc điểm lâm sàng, thang điểm ASPECT của BN Đột quy nhồi máu não không do nguyên nhân từ tim và khảo sát mối liên quan giữa giữa mức độ hồi phục khi ra viện với các thang điểm đột quy.

\section{II. ĐốI TƯỢNG VÀ PHƯƠNG PHÁP NGHIÊN CứU}

1. Đối tượng nghiên cứu. $159 \mathrm{BN}$ Đột quy. nhồi máu não không do nguyên nhân từ tim được điêu trị tại Khoa Đột quy, Bệnh viện Quân y 103 từ tháng 6/2020 đến tháng 1/2021 thỏa mãn các tiêu chuẩn sau.

Tiêu chuẩn lứa chon: BN lần đầu được chẩn đoán là đột quy căn cứ vào định nghĩa của WHO 1970. Tất cả các BN được chụp CT và/ hoặc MRI để xác định là Đột quy nhồi máu não. Thời gian nhập viện trước 7 ngày tính từ khi khởi phát.

Tiêu chuấn loại trừ: BN bị bệnh lý tim như: rối loạn nhịp (rung nhĩ, ngoại tâm thu), rối loạn dẫn truyền, bệnh lý van tim, nhồi máu cơ tim, thiếu máu cơ tim cục bộ, suy tim và các bệnh lý cơ tim. Các bệnh lý mạch máu như: vôi hóa động mach chủ ngực, chủ bụng, tắc mạch chi, mạch phổi, suy tĩnh mạch hai chi dưới. Bị các bệnh lý huyết học và về rối loạn đông, chảy máu; các bệnh lý thần kinh trung ương và tiền sử đã xảy ra đột quy. BN không đồng ý tham gia nghiên cứu.

2. Phương pháp nghiên cứu

- Thiết kế nghiên cứu: mô tả cắt ngang.

- Khám lâm sàng đánh giá các yếu tố nguy 
cơ, triệu chứng lâm sàng khi nhập viện, đánh giá ý thức bằng thang điểm Glasgow, đánh giá mức độ lâm sàng thang điểm NIHSS, đánh giá mức độ hồi phục khi ra viện bằng thang điểm mRS.

- Hình ảnh học: đánh giá đặc điểm tổn thương nhu mô não bằng thang điểm ASPECTS trên phim CT và/ hoặc MRI sọ não.

Xử lý số liệu; số liệu được trình bày dưới dạng số trung bình \pm độ lệch chuẩn hoặc tỷ lệ phần trăm. Giá trị $\mathrm{p}<0,05$ được coi có ý nghĩa thống kê. Xử lý số liệu bằng phần mềm SPSS 22.0 (IBM Inc, Mỹ).

\section{KẾT QUẢ NGHIÊN CỨU VÀ BÀN LUÂ̂N}

1. Đặc điểm chung $B N$ và các yếu tố nguy cở của Đột quy. nhồi máu não. Có rất nhiều yếu tố nguy cơ gây đột quy, theo nghiên cứu của INTERSTROKE bao gồm cả yếu tố nguy cơ không thể điều chỉnh được (tuổi, giới, chủng tộc) và yếu tố nguy cơ có thể điêu chỉnh được (tăng huyết áp, hiện tại hút thuốc, tỷ lệ eo hông, chế độ ăn kiêng, không hoạt động thể chất, tăng lipid máu, đái tháo đường, sử dụng rượu, nguyên nhân tim mạch và Apolipoprotein $B, A 1$ ). [5] Giảm gánh nặng đột quỵ trong cộng đồng đòi hỏi phải xác định các yếu tố nguy cơ có thể điều chỉnh được và chứng minh hiệu quả của các nỗ lực giảm thiểu nguy cơ. [1]

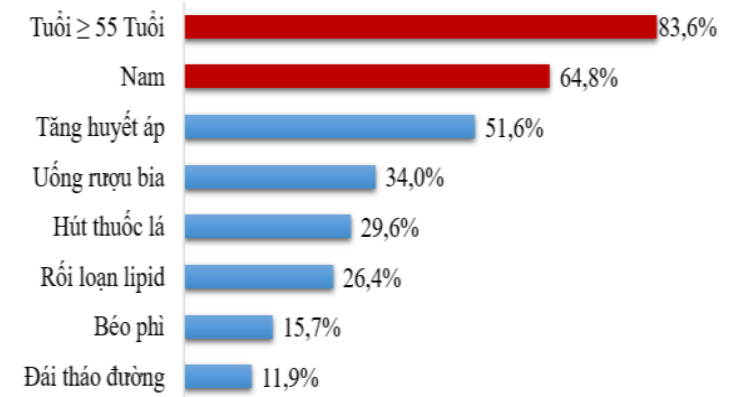

\section{Biểu đồ 1. Đặc điểm chung BN và các yếu tốnguy cơ}

Trong nghiên cứu của chúng tôi, tuổi trung bình của BN đột quy do thiếu máu là 66,04 \pm 12,849 tuổi. Tỷ lệ đột quy tăng theo tuổi, tỷ lệ này tăng gấp đôi trong mối thập niên sau 55 tuổi. [3] Tuổi trung bình của đột quy. do thiếu máu vào năm 2005 là 69,2 tuổi. Tuy nhiên, bằng chứng gần đây cho thấy rằng tỷ lệ mắc và tỷ lệ lưu hành đột quy do thiếu máu đang gia tăng ở nhóm tuổi từ 20 đến 54 tuổi, từ 12,9\% năm 1993/1994 lên 18,6\% năm 2005. [6]

Tỷ lệ nam/ nữ ở là 1,84/1, các nghiên cứu chỉ ra rằng, gần như nam giới bị đột quy do thiếu máu nhiều hơn nữ giới, tỷ lệ nam/ nữ tùy theo từng tác giả và từng quốc gia mà có thể khác nhau. [2] Nghiên cứu gánh nặng bệnh tật toàn cầu GBD 2013 đã xác định tỷ lệ mắc đột quy do thiếu máu nam cao hơn nữ (nam 133/ 100.000 người-năm và nữ 99/ 100.000 người-năm). [1] Mối quan hệ của giới với nguy cơ đột quy phụ thuộc vào độ tuổi. Ở tuổi trẻ, nữ có nguy cơ đột quy cao hơn nam giới. Nghiên cứu của Phạm Phước Sung (2019) nam 64,14 \pm 9,61, nữ 65,71 $\pm 9,99$, tỷ lệ nam/ nữ là 1,44/ 1. [7]

Tăng huyết áp là yếu tố nguy cơ có thể điều chỉnh gặp nhiều nhất $51,6 \%$; hút thuốc lá có $29,6 \%$ BN đột quy do thiếu máu (nam giới $43,7 \%$, nữ giới 3,6\%). Uống rượu bia 34,0\% (nam là $51,5 \%$, nữ là 1,8\%). Theo Pham Phước Sung (2019) các yếu tố nguy cơ có thể thay đổi được ở BN Đột quỵ nhồi máu não: tăng huyết áp $78,8 \%$, đái tháo đường $19,2 \%$, rối loạn lipid $72,7 \%$ và hút thuốc $24,2 \%$. [7] Theo nghiên cứu của Tổ chức đột quy thế giới năm 2019 thì các yếu tố nguy cơ có thể điều chỉnh được của đột quy chung đó là: các yếu tố nguy cơ hội chứng chuyển hóa (huyết áp cao, béo phì, tăng đường máu, tăng cholesterol và giảm mức lọc cầu thận) là $72,1 \%$, do thói quen (hút thuốc, ăn kiêng, lười vận động) là $66,3 \%$, môi trường (ô nhiễm không khí, nhiểm chì) là $28,1 \%$, tăng huyết áp, tăng huyết áp tâm thu đơn độc là $57,3 \%$ và kết hợp tất cả các yếu tố nguy cớ là $88,8 \%$.[3]

2. Đặc điểm lâm sàng Đột quỵ nhôi máu não. Triệu chứng lâm sàng khi nhập viện của nghiên cứu của chúng tôi thể hiện ở biểu đồ 2 . Kết quả cho thấy triệu chứng lâm sàng thường gặp là liệt $1 / 2$ người và liệt dây VII chiếm tỷ lệ nhiều nhất, rối loạn ngổn ngữ cũng là triệu chứng lâm sàng thường gặp lúc nhập viện chiếm $53,5 \%$ BN đột quy do thiếu máu. Các triệu chứng chủ quan như đau đầu, chóng mặt và buồn nôn, nôn ít gặp hơn, các triệu chứng này thường gặp trong đột quy do chảy máu. Các triệu chứng hay gặp do chảy máu như rối loạn ý thức, rối loạn cơ vòng và co cứng mất vỏ, duỗi cứng mất não gặp tỷ lệ rất thấp ở BN đột quy do thiếu máu, đặc biệt chúng tôi không gặp trường hợp nào có dấu hiệu màng não, đây là triệu chứng gần như chỉ điểm của chảy máu não, các triệu chứng lâm sàng biểu hiện tổn thương động mạch não sau như hội chứng tiểu não, dấu hiệu Romberg, dấu hiệu Nystagmus cũng có tỳ lệ rất thấp.

Nghiên cứu của Nguyễn Quang Ân và CS (2018) ở BN đột quy do thiếu máu nhập viện trong 6 giờ đầu cho kết quả, các triệu chứng chủ quan gặp với tuần suất cao hơn như đau đâu $26,9 \%$, chóng mặt $11,9 \%$ và nôn, buồn nôn 
8,2\%. Các triệu chứng khách quan cũng chiếm tỳ lệ cao hơn so với nghiên cứu của chúng tôi như liệt $1 / 2$ người $99,5 \%$, liệt dây VII $91,1 \%$, rối loạn ngôn ngữ 70,9\%, rối loạn ý thức 68,9\%, quay mắt đầu $11,2 \%$. [8] Có sự khác biệt này là do đối tượng nghiên cứu của tác giả Nguyễn Quang Ân là những $B N$ nhập viện trong 6 giờ đầu tiến hành can thiệp lấy tiêu huyết khối, đây là những $B N$ huyết khối động mạch não giữa nên triệu chứng lâm sàng nặng nề hơn.

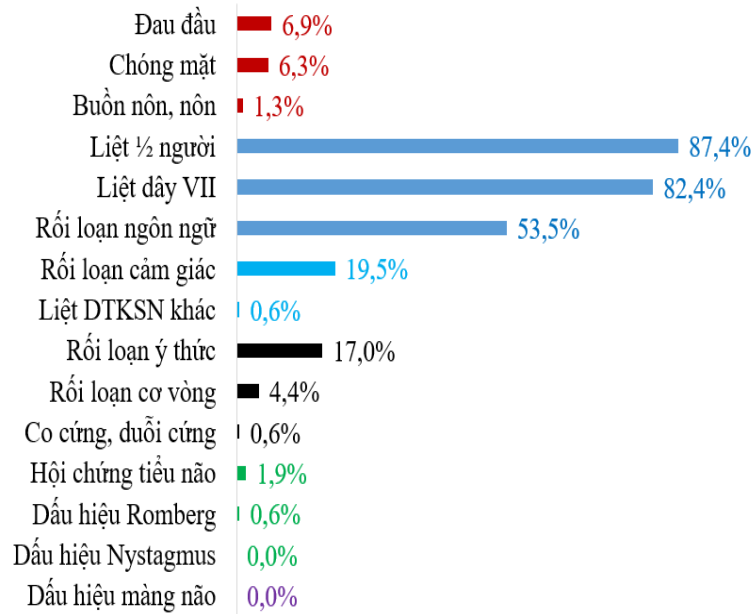

Biểu đồ 2. Triệu chứng lâm sàng khi nhập viện Bảng 1. Các thang điểm lâm sàng

\begin{tabular}{|c|c|c|c|c|}
\hline \multicolumn{2}{|c|}{ Thang điểm } & Điểm & $\begin{array}{c}\text { Số } \\
\text { lương }\end{array}$ & Tỷ lệ \\
\hline \multirow{6}{*}{ GCS } & Tỉnh táo & 15 & 118 & $74,2 \%$ \\
\hline & $\begin{array}{l}\text { Rối loạn } \\
\text { ý thức nhẹ }\end{array}$ & $9-14$ & 40 & $25,2 \%$ \\
\hline & $\begin{array}{l}\text { Rối loạn } \\
\text { ý thức nặng }\end{array}$ & $6-8$ & 0 & $0,0 \%$ \\
\hline & Hôn mê sâu & $4-5$ & 1 & $0,6 \%$ \\
\hline & $\begin{array}{c}\text { Hôn mê rất } \\
\text { sâu }\end{array}$ & 3 & 0 & $0,0 \%$ \\
\hline & $\begin{array}{l}\text { Điểm trung } \\
\text { bình }\end{array}$ & \multicolumn{3}{|c|}{$14,41 \pm 1,31$} \\
\hline \multirow{5}{*}{ NIHSS } & Bình thường & 0 & 1 & $0,6 \%$ \\
\hline & Mức độ nhẹ & $1-4$ & 62 & $39,0 \%$ \\
\hline & Mức đồ vưa & $5-15$ & 78 & $49,1 \%$ \\
\hline & Mức độ nặng & $16-42$ & 18 & $11,3 \%$ \\
\hline & $\begin{array}{l}\text { Điểm trung } \\
\text { bình }\end{array}$ & \multicolumn{3}{|c|}{$7,47 \pm 5,80$} \\
\hline \multirow{5}{*}{$\mathrm{mRS}$} & Tốt & $0-2$ & 115 & $72,3 \%$ \\
\hline & Trung bình & $3-4$ & 34 & $21,4 \%$ \\
\hline & Xấu & 5 & 7 & $4,4 \%$ \\
\hline & $\begin{array}{c}\text { Tử vong, nặng } \\
\text { xin về }\end{array}$ & 6 & 3 & $1,9 \%$ \\
\hline & Điếm trung & bình & 2,19 & 1,34 \\
\hline
\end{tabular}

Đa số BN đột quy do thiếu máu nhập viện với ý thức tỉnh táo (GSC 15 điểm) chiếm $74,2 \%$ chỉ có $25,8 \%$ BN là có rối loạn ý thức (GSC < 15 điểm), trong đó chủ yếu là rối loạn ý thức nhẹ (GSC 9 đến 14 điểm). Mức độ lâm sàng mức nhẹ và bình thường (NIHSS < 5 điểm) chiếm $39,6 \%$, còn lại là mức độ vừa và nặng (NIHSS $\geq 5$ điểm) chiếm $60,4 \%$. Mức độ hồi phục khi ra viện phần lớn $\mathrm{BN}$ ở mức tốt ( $\mathrm{mRS} \leq 2$ điểm) chiếm $72,3 \%$, mức trung bình, xấu, nặng xin về hoặc tử vong ( $\mathrm{mRS}>2$ điểm) chiếm 27,7\%.

Nghiên cứu của Nguyễn Quang Ân (2018) cho điểm NIHSS trung bình 17,37 $\pm 6,8$ điểm, tỷ lệ điểm NIHSS $\geq 6$ chiếm $94,8 \%$, cao hơn nghiên cứu của chúng tôi.[8] Nghiên cứu của Đoàn Vũ Xuân Lộc (2014) điểm mRS trung bình khi ra viện là $2,28 \pm 1,33$ điểm, trong đó $m R S \leq$ 2 điểm chiếm 62,7\%.[9] Còn nghiên cứu của Esmael (2021) ở 150 BN Đột quy. nhồi máu não

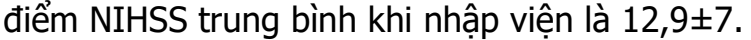

3. Thang điểm ASPECT của Đột quy nhồi máu não. Trong $159 \mathrm{BN}$ Đột quy nhồi máu não của nghiên cứu chúng tôi có 124 BN chụp CT sọ não, 79 BN chụp MRI sọ não và $44 \mathrm{BN}$ chụp cả $C T$ và $M R I$, không có $B N$ nào không chụp $C T$ và/ hoặc MRI sọ não. Phân bổ tỷ lệ điểm ASPECT trên phim CT, MRI của BN Đột quỵ nhồi máu não thể hiện ở biểu đồ 4.

Điểm ASPECT trung bình của BN Đột quỵ nhồi máu não trong nghiên cứu của chúng tôi là 8,05 $\pm 1,395$ điểm, trong đó ASPECT > 7 điểm chiếm tỷ lệ nhiều hơn $(71,7 \%)$ so với điểm ASPECT $\leq 7$ điểm $(28,3 \%)$. Nghiên cứu của Nguyễn Quang Ân (2018) điểm ASPECT trung bình là $7,87 \pm 1,39$, ASPECT > 7 điểm chiếm $61,9 \%$, tương đương với nghiên cứu chúng tôi. [8] Nghiên cứu của Esmael (2021) là 12,9 \pm 7 điểm.

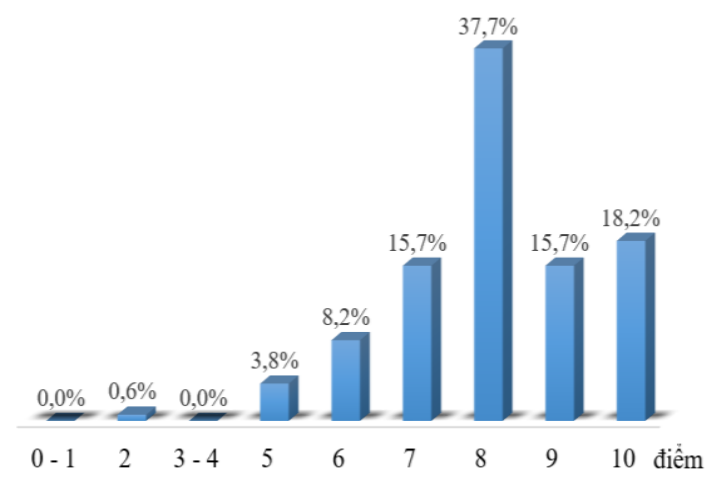

Biểu đồ 3. Tỷ lệ điểm ASPECT của Đột quY. nhồi máu não

4. Mối liên quan giữa mức độ hồi phục khi ra viện với các thang điểm đột quy.

Qua khảo sát chúng tôi nhận thấy khồng có mối liên quan giữa các yếu tố nguy cơ, triệu 
chứng lâm sàng khi nhập viện với mức độ hồi phục khi nhập viện của BN Đột quỵ. nhồi máu

não. Bảng 2 thể hiện mối liên quan giữa mức độ

hồi phục khi ra viện với các thang điểm đột quy.

Bảng 2. Môi liên quan với mức độ hồi phuc ra viện (mRS) với các thang điểm đột quy.

\begin{tabular}{|c|c|c|c|c|c|}
\hline \multirow{2}{*}{ Thang điểm } & \multirow{2}{*}{ Điểm } & \multicolumn{2}{|c|}{ Điếm mRS ra viện } & \multirow[b]{2}{*}{$\mathbf{p}$} & \multirow{2}{*}{$\begin{array}{c}\text { OR } \\
(95 \% \mathrm{CI})\end{array}$} \\
\hline & & $\mathrm{mRS} \leq 2$ & $m R S>2$ & & \\
\hline GCS & 15 & 93 & 25 & 0,002 & 3,2 \\
\hline GLS & $<15$ & 22 & 19 & 0,002 & $(1,5-6,8)$ \\
\hline NIHSS & $<5$ & 61 & 6 & $<0,001$ & 7,2 \\
\hline & $\geq 5$ & 54 & 38 & & $(2,8-18,2)$ \\
\hline ASPECT & $\begin{array}{l}>7 \\
\leq 7\end{array}$ & $\begin{array}{l}88 \\
27\end{array}$ & $\begin{array}{l}26 \\
18\end{array}$ & 0,029 & $2,3(1,1-4,7)$ \\
\hline
\end{tabular}

Như vậy cả 3 thang điểm GCS, NIHSS và ASPECT đều có mối tương quan với thang điểm mRS khi ra viện.

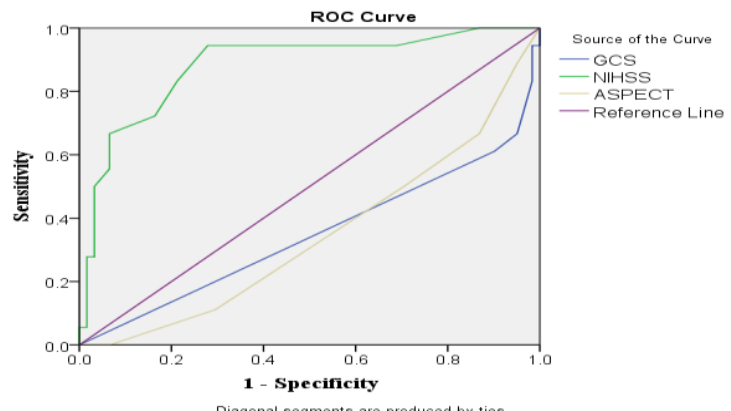

Biểu đồ 4. Đường cong ROC giữa mức độ hồi phục khi ra viện với các thang điểm

Phân tích ROC giữa mức độ hồi phục khi ra viện (mRS) với các thang điểm chúng tôi thấy: Thang điểm NIHSS cho kết quả tốt nhất với AUC
$=0,881, p<0,001$; thang điểm ASPECT AUC $=$ $0,344, p=0,045$ và với thang điểm Glasgow $A U C=0,347, p=0,050$.

Tại điểm cut-off NIHSS $=6$ điểm thì chỉ số MaxJ $=0,666$, Se $=94,4 \%, \mathrm{Sp}=72,1 \%$, OR $=$ $37,9(8,7-164,7)$ với $\mathrm{p}<0,01$ nghĩa là BN đột quy do thiếu máu có thang điểm NIHSS $<6$ ra viên hồi phục tốt (mRS $\leq 2)$ gấp 37,9 lần $B N$ có điểm NIHSS $\geq 6$.

Tuy nhiên khi phân tích tương quan hồi quy logistic đa biến đánh giá mức độ hồi phục khi ra viện (mRS) với các thang điểm Glassgow, NIHSS, ASPECT thì chỉ có thang điểm NIHSS có sự tương quan hồi quy với mức độ hồi phục khi ra viện (bảng 4) với độ dự báo chính xác của mô hình là $84,8 \%$, giá trị $\mathrm{p}=0,001$.

Bảng 4. Tương quan logicitic giữa thang điểm mRS với các thang điểm đột quy.

\begin{tabular}{|c|c|c|c|c|c|c|c|c|c|}
\hline & \multirow[b]{2}{*}{ B } & \multirow[b]{2}{*}{ S.E. } & \multirow[b]{2}{*}{ Wald } & \multirow[b]{2}{*}{ df } & \multirow[b]{2}{*}{ Sig. } & \multirow[b]{2}{*}{$\operatorname{Exp}(B)$} & \multicolumn{2}{|c|}{$95 \%$ C.I.for EXP(B) } \\
\hline & & & & & & & & Lower & Upper \\
\hline \multirow[t]{3}{*}{ Step $1^{a}$} & GCS & .676 & .525 & 1.655 & 1 & .198 & 1.966 & .702 & 5.503 \\
\hline & ASPECT & .114 & .315 & .132 & 1 & .716 & 1.121 & .605 & 2.077 \\
\hline & Constant & -15.176 & 8.759 & 3.002 & 1 & .083 & .000 & & \\
\hline
\end{tabular}

a. Variable(s) entered on step 1: GCS, NIHSS, ASPECT.

Như vậy đánh giá mức đô lâm sàng bằng thang điểm NIHSS khi nhập viện có giá trị tiên đoán mức độ hồi phục khi ra viện của BN đột quy thiếu máu; khi điểm NIHSS tẳng lên 1 điểm thì xác suất $B N$ ra viện hồi phục xấu $(\mathrm{mRS}>2)$ tăng lên $1,54(1,19-1,99)$ lần, với $p=0,001$.

Nghiên cứu của Đoàn Vũ Xuân Lộc và CS (2014) cho thấy có mối tương quan chặt giữa thang điểm APSECT với thang điểm mRS ở BN đột quy. thiếu mãu não cấp. [9] Nghiên cứu của Esmael (2021) có mối liên quan giữa thang điểm ASPECT với thang điểm $m R S$ và NIHSS.

\section{KẾT LUÂN}

Có mối liên quan giữa mức độ hồi phục khi ra viện theo thang điểm mRS với thang điểm GCS $(p=0,002$, OR $=3(1,5-6,8))$, NIHSS $(p<$ $0,01, \mathrm{OR}=7,2(2,8-18,2))$ và $\mathrm{ASPECT}(\mathrm{p}=$ $0,029, \mathrm{OR}=2,3(1,1-4,7))$. Tuy nhiên chỉ có thang điểm NIHSS có tương quan logistic với mRS và có giá trị dự báo được mức độ hồi phục ra viện.

\section{TÀI LIẸU THAM KHẢO}

1. Feigin Valery $L_{1}$, Norrving Bo, and Mensah George A. (2017). Global Burden of Stroke. Circulation Research, 120(3), 439-448.

2. Boehme Amelia K., Esenwa Charles, and Elkind Mitchell S.V. (2017). Stroke Risk Factors, Genetics, and Prevention. Circulation Research, 120(3), 472-495. 
3. Lindsay M.P., Norrving B., Sacco R.L., et al. (2019). World Stroke Organization (WSO): Global Stroke Fact Sheet 2019. Int J Stroke, 14(8), 806-817.

4. Feigin V.L., Krishnamurthi R.V., Parmar $P_{\text {., }}$ et al. (2015). Update on the Global Burden of Ischemic and Hemorrhagic Stroke in 1990-2013: The GBD 2013 Study. NED, 45(3), 161-176.

5. O'Donnell M.J., Chin S.L., Rangarajan S., et al. (2016). Global and regional effects of potentially modifiable risk factors associated with acute stroke in 32 countries (INTERSTROKE): a case-control study. Lancet, 388(10046), 761-775.

6. Kissela B.M., Khoury J.C., Alwell K., et al. (2012). Age at stroke: Temporal trends in stroke incidence in a large, biracial population. Neurology, 79(17), 1781-1787.
7. Phạm Phước Sung (2019), Kết quả điều trị nhồi máu não trong giai đoan tứ 3 đến 4,5 giờ bằng thuốc tiêu huyết khối Ailteplase liều thấp, Luận án tiến sĩ Trường Đại học Y Hà Nội.

8. Nguyễn Quang Ân, Nguyễn Minh Hiên, Nguyễn Hoàng Ngọc, et al. (2018). Nghiên cứu mối liên quan giữa đắc điểm lâm sang và hình ảnh cắt lớp vi tính ở bệnh nhân Đột quy nhồi máu não cấp trong 6 giờ đầu kể từ khi khởi phát. Tap chí Y Dước hoc quân sự, 4, 84-92.

9. Đoàn Vũ̃ Xuân Lộc, Nguyễn Thanh Thảo, Hoàng Minh Lợi, et al. (2014). Ứng dụng thang điểm ASPECTS trong tiên lượng sớm dự hậu đột quy nhồi máu não cấp. Tap chí $Y$ Dược hoc Trường Đại học Y Dược Huế, 22 + 23, 169 (9).

\section{YẾU TỐ TIÊN LƯỢNG THÀNH CÔNG CUẢ PHƯƠNG THỨC AVAPS Ở BÊ̂NH NHÂN ĐợT CẤP BỆNH PHỔI TẮC NGHẼN MẠN TÍNH (COPD) ĐƯợC THÔNG KHÍ NHÂN TẠO KHÔNG XÂM NHÂ̂P}

\section{TÓM TẮT.}

Mục tiêu: Đánh giá yếu tố tiên lượng thành công của bểnh nhân đợt cấp bệnh phổi tắc nghẽn mạn tính (COPD) được thổng khí nhân tạo không xâm nhập bằng phương thức AVAPS. Phương pháp: Nghiển cứu tiến cứu so sánh trước sau can thiệp trên 40 bệnh nhân đợt cấp COPD nhập khoa Cấp cứu bệnh viện Bạch Mai có chỉ định thông khí không xâm nhập từ tháng 05/2019 đến tháng 8/2020. Các thông số theo dõi chính như tuổi, giới, các chỉ số khí máu: $\mathrm{pH}$, $\mathrm{PaCO}_{2}, \mathrm{PaO}_{2}, \mathrm{HCO}_{3}, \mathrm{PaO}_{2} / \mathrm{FiO}_{2}$, các thông số thở máy: Vt, Vte, PIP, Leak được thu thập tại các thời điểm: trước thở AVAPS, sau thở AVAPS 3 giờ, sau 6 giờ, sau 12 giờ. Bệnh nhân được đánh giá thành công khi không phải đặt nội khí quản, lâm sàng và khí máu ổn định sau bỏ máy 24 giờ. Kết quả: Nghiên cứu trên 40 bệnh nhân (tuổi trung bình 70,3 $\pm 9,87$ tuổi; 7,5\% nữ giới) cho kết quả có $29(72,5 \%)$ bệnh nhân thở máy thành công. Ở nhóm thành công, PaCO2, HCO3, PIP, Leak giảm dân theo thời điểm theo dõi, giảm nhanh nhất từ T0 đến T3-6; Vt, Vte tăng dần $(p<0,05)$; Ở nhóm thất bai PaCO2, PaO2, PIP, Vt, Vte tăng dấn theo thời điểm. $\mathrm{PaCO}_{2}$ với điểm cắt $\geq 88 \mathrm{mmHg}$ (diên tích dưới đường cong ROC, AUC $=0,8364$ ), PIP với điểm cắt $\geq 17 \mathrm{cmH}_{2} \mathrm{O}$ (AUC=0,8871), Leak với điểm cắt $\geq 29$ lít/phút (AUC $=0,7884)$, cho độ nhạy, độ đặc hiệu, giá trị dự báodương tính và giá trị dự báo ẩm tính cao. Kết luận: Các thông số như PaCO2, PIP và leak tại thời điểm bắt

\footnotetext{
${ }^{1}$ Trung tâm Cấp cứu A9- Bênh viên Bach Mai,

${ }^{2}$ Trung tâm Chống độc - Bệnh viện Bạch Mai

${ }^{3}$ Bệnh viện Đa khoa Nông Ñghiệp
}

Chịu trách nhiệm chính: Đố Ngọc Sơn

Email: sonngocdo@gmail.com

Ngày nhận bài: 9.3.2021

Ngày phản biên khoa học: 28.4.2021

Ngày duyệt bài: 7.5.2021

\section{Đỗ Ngọc Sơn ${ }^{1}$, Đặng Thị Xuân ${ }^{2}$, Vũ Trung Kiên ${ }^{3}$}

đâu tiến hành thở AVAPS là những yếu tố tiên lượng thành công khi thông khí nhân tạo không xâm nhập cho bệnh nhân đợt cấp COPD.

Ti̛ khóa: Thông khí nhân tao không xâm nhập, AVAPS, đợt cấp bệnh phổi tắc nghẽn mạn tính

\section{SUMMARY}

\section{SUCCESSFUL PREDICTION FACTORS OF AVAPS IN PATIENTS WITH THE ACUTE EXACERBATION OF CHRONIC PULMONARY OBSTRUCTIVE DISEASE (COPD) ON NON- INVASIVE MECHANICAL VENTILATION}

Objective: to identify a successful prediction factors in patients with exacerbation of chronic obstructive pulmonary disease (COPD) who were on noninvasive mechanical ventilation by Average Volume Assured Pressure Support (AVAPS) mode. Methods: A prospective, pre \& post-intervention comparison study on 40 non-invasive ventilated patients with COPD exacerbations admitted to the Emergency Department of Bach Mai Hospital from May 2019 to August 2020. The main variables such as age, sex, blood gas indices: $\mathrm{pH}, \mathrm{PaCO} 2, \mathrm{PaO} 2, \mathrm{HCO}$, $\mathrm{PaO} 2 / \mathrm{FiO} 2$ ratio, mechanical ventilation parameters: Vt, Vte, PIP, Leak were collected at the timelines: before AVAPS, 3 hours, 6 hours, 12 hours after AVAPS. Successful ventilation was defined as no requirement for endotracheal intubation, clinical and blood gas stability within 24 hours. Results: The study on 40 patients (mean age $70.3 \pm 9.87$ years; $7.5 \%$ women) showed that there were $29(72.5 \%)$ patients with successful ventilation. In the successful group, $\mathrm{PaCO} 2, \mathrm{HCO} 3, \mathrm{PIP}$, Leak levels decreased gradually, the fastest decrease was occurred from T0 to T3-6; Vt, Vte levels increased gradually ( $p<0.05)$; In the failed group PaCO2, PaO2, PIP, Vt, Vte levels increased gradually, leak level decreased gradually ( $p$ 